This is the peer reviewed version of the following article: Fancey, $K . S$. and Fazal, A. (2016), Prestressed polymeric matrix composites: Longevity aspects. Polym. Compos., 37: 2092-2097. doi:10.1002/pc.23387, which has been published in final form at https://doi.org/10.1002/pc.23387 . This article may be used for non-commercial purposes in accordance with Wiley Terms and Conditions for Use of Self-Archived Versions." 


\title{
Prestressed polymeric matrix composites: Longevity aspects
}

\author{
Kevin S. Fancey*, Adnan Fazal \\ School of Engineering, University of Hull, Hull HU6 7RX, United Kingdom
}

\begin{abstract}
Elastically pre-stressed polymeric matrix composites (EPPMCs) are produced by stretching fibers (e.g. glass) within the composite during matrix curing. The resulting pre-stress can enhance mechanical performance, without increasing section dimensions or weight. Viscoelastically pre-stressed polymeric matrix composites (VPPMCs) can provide similar benefits, these being produced by subjecting polymeric fibers (e.g. nylon 6,6) to a creep load, which is released prior to molding. Although VPPMCs offer simplified processing and flexibility in product geometry, long-term viscoelastic activity within the pre-stressing fibers is sensitive to time-temperature limitations. In this study, nylon 6,6 fiber-polyester resin samples were subjected to accelerated ageing. Using time-temperature superposition, the samples were maintained at $70^{\circ} \mathrm{C}$ for $2298 \mathrm{~h}$, representing a 20 -fold ageing increase over previous work. Subsequent Charpy impact testing (at $20^{\circ} \mathrm{C}$ ) demonstrated that the VPPMC samples absorbed $\sim 40 \%$ more energy than corresponding control (unstressed) counterparts; i.e. no deterioration in impact performance was observed, over a duration equivalent to $\sim 25$ years at $50^{\circ} \mathrm{C}$. In contrast, the longevity of EPPMCs remains unknown, but it is suggested that progressive localized matrix creep at the fiber-matrix interface regions may cause a deterioration in elastically generated pre-stress with time and/or elevated ambient temperatures.
\end{abstract}

*Tel: +44-1482-465071; fax: +44-1482-466664.

E-mail address: k.s.fancey@hull.ac.uk

\section{Introduction}

Elastically pre-stressed polymeric matrix composites (EPPMCs) are comparable to pre-stressed concrete, in that fibers within the composite are stretched to maintain an elastic strain during matrix curing. Compressive stresses are produced within the matrix on solidification, counterbalanced by residual fiber tension. Whilst early EPPMC studies were focused on laminates [1,2], later investigations with unidirectional glass fiber EPPMCs have indicated increases in tensile strength and elastic modulus of $\sim 25 \%$ and $\sim 50 \%$ respectively [3], compared with unstressed counterparts. Moreover, impact resistance and flexural properties (stiffness and strength) have been found to increase by up to $33 \%[4,5]$. These improvements are explained by the residual stresses (i) 
impeding or deflecting propagating cracks and (ii) reducing strains within the composites from external tensile or bending loads [3-5]. More recent investigations include unidirectional glass fiber EPPMCs as potential dental materials, the pre-stress increasing flexural strength by $\sim 30 \%$ [6] and unidirectional carbon fiber EPPMCs, with increases of $30 \%$ in impact toughness [7]. In addition to opportunities for EPPMCs to improve mechanical properties (without the need to increase section dimensions or weight), there has been interest in their use as bistable (morphing) composites, either as pre-stressed laminates [8] or as unidirectional fiber pre-stressed structural elements [9].

Despite the benefits elastic pre-stressing may offer, the need to apply fiber tension whilst the matrix cures may cause fiber length, orientation and spatial distribution to be restricted, which compromises mold geometry [10]. Moreover, stretching rig design with appropriate fiber clamping can be technically challenging $[8,11]$. A potential major limitation to the use of EPPMCs however, arises from the matrix being polymeric: localized creep at the fiber-matrix interface regions may be expected, in response to the elastically generated pre-stress, so that there could be a progressive deterioration in this pre-stress with time [10].

Viscoelastically pre-stressed PMCs (VPPMCs) avoid the need for simultaneous fiber stretching and molding operations. Instead, polymeric fibers are subjected to tensile (viscoelastic) creep and the creep load is released before the fibers are molded into a matrix. On solidification, the previously strained fibers continue to attempt viscoelastic recovery; this produces compressive stresses in the matrix, which are counterbalanced by residual tension within the fibers, similar to an EPPMC. Since fiber stretching and molding operations are de-coupled, a key benefit is the flexibility that VPPMC production can offer: relatively simple equipment is required for applying a creep load to fiber tow and following load release, the fibers can be chopped to any length and placed in any orientation within any shape of mold that can be filled with a matrix resin.

Using nylon 6,6 fibers, VPPMC samples absorb typically 25-30\% more impact energy from Charpy impact tests than their control (unstressed) counterparts, with some samples reaching increases of $50 \%$ [10,12-16]. Other mechanical tests have shown that these VPPMCs possess improved properties over their control equivalents, i.e. increases in tensile strength, modulus and energy absorption exceeding $15 \%, 30 \%$ and $40 \%$ respectively [17] and $\sim 50 \%$ higher flexural modulus [18]. As well as nylon fiber-based VPPMCs, other researchers have successfully demonstrated VPPMCs based on bamboo, which increased flexural toughness by $28 \%$ [19]. Our most recent published research has focused on VPPMCs using ultra-high molecular weight polyethylene (UHMWPE) fibers; we have found increases of $20-40 \%$ in flexural modulus [20] and Charpy impact energy absorption [21]. Therefore, various reinforcements may hold promise; however, nylon fiber-based VPPMCs are, to date, the most established.

In addition to production flexibility, a key advantage of VPPMCs is that any potential for deterioration through localized matrix creep would be offset by an active response from longer term viscoelastic recovery mechanisms within the polymeric fibers [10]. Nevertheless, there is potentially a major limitation with VPPMCs, in that viscoelastic activity is temperature-sensitive. Thus high-temperature curing cycles or lengthy exposures to hot ambient conditions could damage or at least accelerate the viscoelastic recovery mechanisms, which may render the pre-stress ineffective. Therefore, despite the benefits that VPPMC principles may offer, time-temperature limitations could impede the development of VPPMC technology into practical 
composite structures. This paper addresses further investigations (by Charpy impact testing) using time-temperature superposition techniques.

\section{Background and development of ageing parameters}

\section{Long-term viscoelastic activity}

To offset the potential for deterioration in pre-stress from matrix creep (especially at the fiber-matrix interface), the fibers within a VPPMC should be capable of long-term viscoelastic recovery. For polymeric fibers, this capability can be determined from recovery strain measurements resulting from creep loading conditions used for VPPMC production. Fig. 1 shows recovery strain data, measured at $20^{\circ} \mathrm{C}$, for nylon 6,6 fiber as untwisted continuous yarn [14,15]. Full details are available in Refs. [14,15] but the main points are summarized here. Recovery strain becomes insignificant for nonannealed (i.e. as-received) yarn within $1000 \mathrm{~h}$ of releasing the creep stress; however, annealing the yarn prior to creep $\left(150^{\circ} \mathrm{C}\right.$ for $\left.0.5 \mathrm{~h}\right)$ causes viscoelastic recovery to remain active over a much longer timescale. The gray data points in Fig. 1 represent strain measurements taken in real time, up to 4 years. To go beyond a few years, accelerated ageing techniques are required and these were used to obtain the black data points, up to the equivalent of 100 years at $20^{\circ} \mathrm{C}$. It is clear from Fig. 1 that the data from real-time and accelerated ageing show good agreement and the curve, fitted to the black data points, represents the following equation for recovery strain as a function of time, $t$ :

$$
\varepsilon_{\mathrm{rvis}}(t)=\varepsilon_{\mathrm{r}}\left[\exp \left(-\left(\frac{t}{\eta_{\mathrm{r}}}\right)^{\beta_{\mathrm{r}}}\right)\right]+\varepsilon_{\mathrm{f}}
$$

Eq. (1) is based on the Weibull or Kohlrausch-Williams-Watts (KWW) function, in which polymeric deformation can be represented by a model consisting of timedependent mechanical latch elements [22,23]. The permanent strain from viscous flow, $\varepsilon_{\mathrm{f}}$, is a residual strain as recovery time $t$ approaches $\infty$. For viscoelastic strain recovery, the $\varepsilon_{\mathrm{r}}$ function depends on the Weibull shape parameter, $\beta_{\mathrm{r}}$, and characteristic life, $\eta_{\mathrm{r}}$, and the resulting parameter values are shown in Fig. 1 . Since $\varepsilon_{\mathrm{f}}$ is predicted to be close to zero $\left(<10^{-4} \%\right)$, virtually all available recovery is viscoelastic, indicating that viscous flow would have an insignificant effect on the viscoelastic prestressing mechanism. By extrapolating to $8.766 \times 10^{6} \mathrm{~h}$ (1000 years), Eq. (1) predicts $\varepsilon_{\mathrm{rvis}}(t)$ to be $0.185 \%$, i.e. three orders of magnitude greater than $\varepsilon_{\text {f. }}$. Thus viscoelastic activity, under these conditions, is a long-term phenomenon.

Although Fig. 1 demonstrates long-term viscoelastic activity, it provides no information on the associated force output from such fibers constrained within the VPPMC matrix. In a separate study, the force-time relationship was determined by monitoring force output from viscoelastically recovering nylon 6,6 yarn [24]. Here, annealed yarn was subjected to a $24 \mathrm{~h}$ creep stress of $320 \mathrm{MPa}$ and, following stress removal, the loose yarn was allowed to contract to a fixed strain, from which the recovery force could then be monitored. The main finding from Ref. [24] was that the viscoelastic recovery force increased with time (to $2700 \mathrm{~h}$ ), and was predicted to reach a limiting value of $12 \mathrm{MPa}$ (i.e. $3.8 \%$ of applied stress) as $t$ approached $\infty$. Subsequent 
monitoring to $25000 \mathrm{~h}$ has shown force output to progress in accordance with this trend [15].

Although recovery strain measurements (Fig. 1) can be made from samples subjected to accelerated ageing, strain measurements beyond the equivalent of 100 years at $20^{\circ} \mathrm{C}$ become impractical; thus Eq. (1) must be relied upon to predict values over longer timescales. Moreover, if accelerated ageing techniques could be applied to viscoelastic recovery force measurements, the results may further verify earlier findings, that force grows to a limiting value with time [24] but they would not necessarily relate to the long-term behavior of a VPPMC, since matrix behavior is not accounted for. Therefore, the only alternative is to subject VPPMC samples (and control counterparts) directly to accelerated ageing: these can then be evaluated, by Charpy impact testing, for evidence of any deterioration in performance with age.

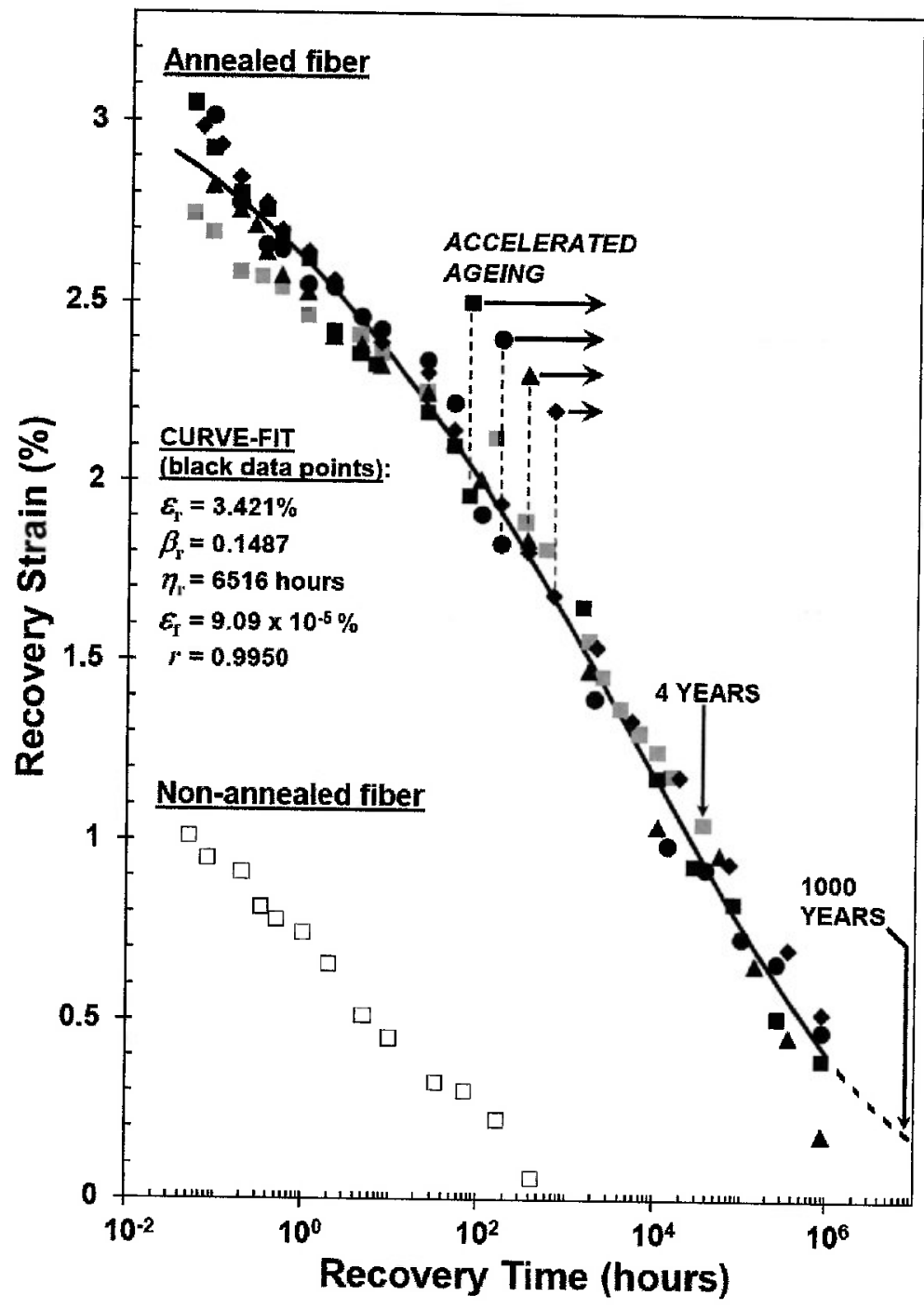

FIG. 1. Recovery strain data at $20^{\circ} \mathrm{C}$ from nylon 6,6 yarn following $24 \mathrm{~h}$ creep at $342 \mathrm{MPa}$. For yarn annealed prior to creep, gray data points were measured in real time up to $3.5 \times 10^{4} \mathrm{~h}$ (4 years); black data points are from four samples, each subjected to periods of accelerated ageing initiated at different recovery times (as shown), up to $9 \times 10^{5} \mathrm{~h}$ (100 years). The curve shows Eq. (1) fitted to the black data, with listed parameters and $r$, the correlation coefficient; after Refs $[14,15]$. 


\section{Time-temperature superposition}

If a polymeric fiber is subjected to creep, the subsequent viscoelastic recovery rate can be expected to increase if temperature is raised and this corresponds with timetemperature superposition principles. For many polymers, the effect enables accelerated ageing to be undertaken, if the appropriate shift factor, $\alpha_{\mathrm{T}}$, is known. Here, $\alpha_{\mathrm{T}}$ equates an elevated temperature to a shift in time (ageing). From published data on creep [25] and stress relaxation [26] for nylon 6,6 fiber, a linear relationship between $\log \alpha_{\mathrm{T}}$ and temperature allows $\alpha_{\mathrm{T}}$ to be obtained over a suitable temperature transition. Thus $\log \alpha_{\mathrm{T}}$ was found to be 3.577 at $60^{\circ} \mathrm{C}$ relative to $20^{\circ} \mathrm{C}$; i.e. rates of creep, stress relaxation or some other measure of viscoelastic activity would be 3776 times faster at $60^{\circ} \mathrm{C}$ relative to $20^{\circ} \mathrm{C}$ [14].

By subjecting samples of viscoelastically recovering nylon 6,6 yarn to periods of $60^{\circ} \mathrm{C}$, this $\alpha_{\mathrm{T}}$ value was used to acquire the accelerated ageing data in Fig. 1. As stated earlier however, recovery strain measurements beyond the equivalent of 100 years at $20^{\circ} \mathrm{C}$ become impractical, hence Charpy impact testing of aged VPPMC samples becomes the most viable option. In previous work [15], batches of VPPMC samples and their control counterparts were subjected to periods of $60^{\circ} \mathrm{C}$ for more than 3 months, prior to Charpy impact testing at $20^{\circ} \mathrm{C}$. These results demonstrated no deterioration in impact performance over a duration equivalent to $20^{\circ} \mathrm{C}$ for 1000 years or $40^{\circ} \mathrm{C}$ for 20 years. In the current work, this time-temperature envelope for VPPMC durability is extended further, by up to 20 -fold.

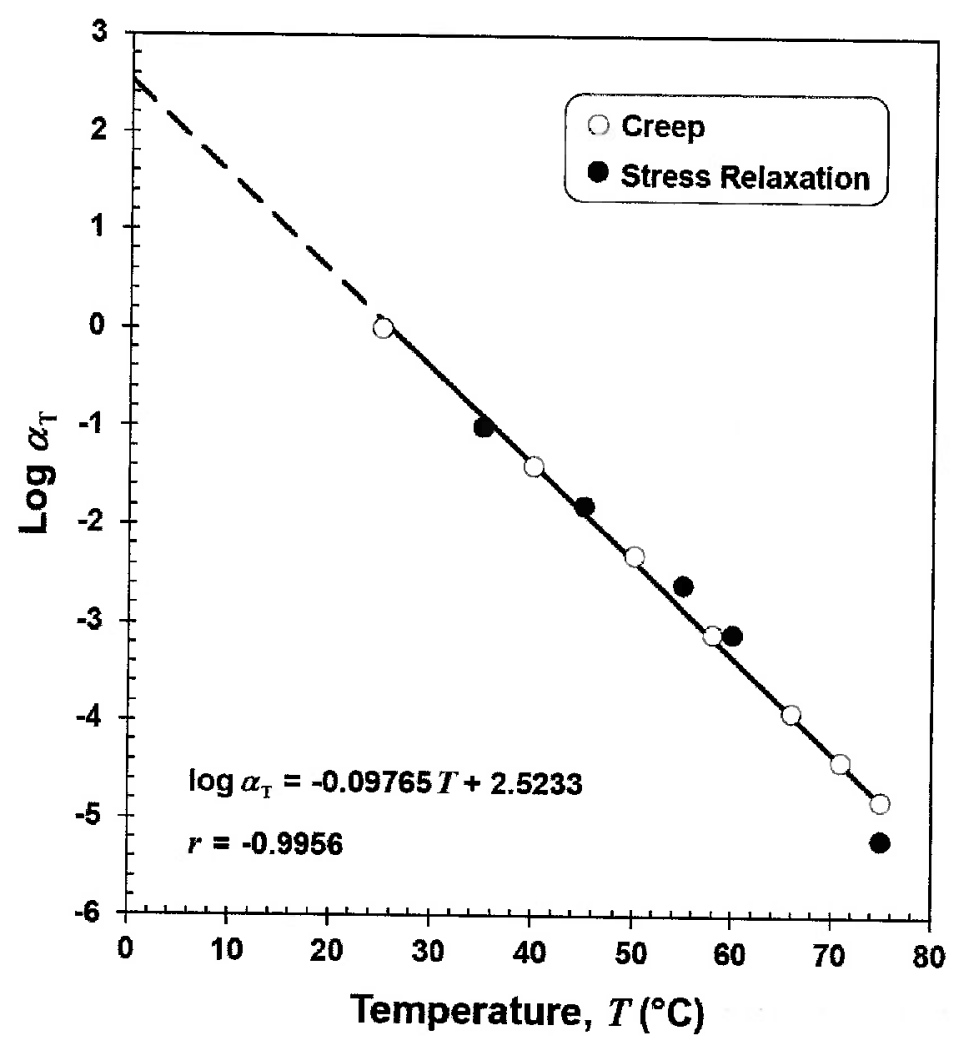

FIG. 2. Plot of the time-temperature shift factor, $\alpha_{\mathrm{T}}$, as a function of test temperature (data range 25$75^{\circ} \mathrm{C}$ ) using published data for creep [25] and stress relaxation [26] in nylon 6,6 fiber. Reference temperature $\left(\log \alpha_{\mathrm{T}}=0\right)$ was $25^{\circ} \mathrm{C}$. The line-fit and equation are from linear regression; $r$ is the correlation coefficient. This is revised from a previous plot (data range $25-60^{\circ} \mathrm{C}$ ) [14]. 
To provide a significant increase in accelerated ageing within an acceptable period $\left(\sim 3\right.$ months) requires the ageing temperature to be higher than $60^{\circ} \mathrm{C}$. Fig. 2 shows the previously adopted $\log \alpha_{\mathrm{T}}$ versus temperature plot $\left(25-60^{\circ} \mathrm{C}\right)$ [14] extended to show data from creep and stress relaxation $[25,26]$ up to $75^{\circ} \mathrm{C}$. This enables $\log \alpha_{\mathrm{T}}$ to be determined at $70^{\circ} \mathrm{C}$ relative to $20^{\circ} \mathrm{C}$. Linear regression to $75^{\circ} \mathrm{C}$ gives a slightly steeper gradient of -0.09765 in Fig. 2, compared with -0.08943 to $60^{\circ} \mathrm{C}$ [14] and the resulting $\log \alpha_{\mathrm{T}}$ value for a $20-70^{\circ} \mathrm{C}$ transition is 4.8825 . Therefore, viscoelastic activity would be 76300 times faster at $70^{\circ} \mathrm{C}$ relative to $20^{\circ} \mathrm{C}$. Thus by subjecting VPPMC samples (with control counterparts) to $70^{\circ} \mathrm{C}$ for $2298 \mathrm{~h}$ (i.e. $\sim 3.2$ months), the pre-stress effect from viscoelastic recovery mechanisms will be aged to the equivalent of 20000 years at $20^{\circ} \mathrm{C}$, based on data from Fig. 2. By using the parameter values shown in Fig. (1), Eq. (1) at $1.753 \times 10^{8} \mathrm{~h}$ (20000 years) predicts $\varepsilon_{\text {rvis }}(t)$ to be very low, i.e. $0.036 \%$; nevertheless, this is is still $\sim 400$ times greater than $\varepsilon_{\mathrm{f}}$.

\section{Experimental}

Fiber reinforcement was from continuous untwisted multi-filament nylon 6,6 yarn (140 filaments, $27.5 \mu \mathrm{m}$ filament diameter), supplied by Goodfellow Cambridge Ltd, UK. The nylon yarn was annealed in a fan-assisted oven $\left(150^{\circ} \mathrm{C}, 0.5 \mathrm{~h}\right)$; this was essential for long-term viscoelastic recovery, as shown in Fig. 1. Moreover, to enable direct comparison, nylon yarn designated for unstressed 'control' samples was also annealed at the same time. Nylon yarn designated for (pre-stressed) 'test' samples was attached to a bespoke stretching rig and subjected to $340 \mathrm{MPa}$ tensile creep stress for 24 $\mathrm{h}$, whilst equivalent (annealed) control yarn was positioned in close proximity to the stretching rig for exposure to the same ambient conditions $\left(19.5-21^{\circ} \mathrm{C}, 30-50 \% \mathrm{RH}\right)$. On releasing the creep load, each yarn was folded, cut into lengths of $\sim 500 \mathrm{~mm}$ and combed (brushed) into flat ribbons ready for molding.

The matrix material was a clear-casting polyester resin, as used in recent work $[16,20,21,27]$, i.e. Cray Valley Norsodyne E9252, mixed with $1 \%$ MEKP catalyst, supplied by CFS Fibreglass, UK. Gel-time (room temperature) was $\sim 0.25 \mathrm{~h}$. Unidirectional continuous fiber composites were open-cast in two aluminum molds, the process being completed within $0.5 \mathrm{~h}$ of the fiber stretching procedure. Each mold had a $10 \mathrm{~mm}$ wide channel for casting a $460 \mathrm{~mm}$ strip of test and control materials simultaneously from the same resin mix, to produce one batch. Following demolding (after $\sim 2 \mathrm{~h}$ ), the composite strips were each cut into five equal $(80 \mathrm{~mm})$ lengths and held under a weighted steel strip for $24 \mathrm{~h}$ to prevent any risk of stress-induced sample distortion.

Each batch consisted of five test and five control samples, the sample dimensions being $80 \times 10 \times 3.2 \mathrm{~mm}$, all with a fiber volume fraction, $V_{\mathrm{f}}$, of $2.2 \%$. These were stored at room temperature $\left(19-22^{\circ} \mathrm{C}\right)$ in polythene bags for $336 \mathrm{~h}(2$ weeks $)$ prior to them being subjected to accelerated ageing. A muffle furnace was used for accelerated ageing; this was calibrated for operation at $70^{\circ} \mathrm{C}$ and checked for long-term temperature stability $\left( \pm 0.5^{\circ} \mathrm{C}\right)$. Composite samples were placed as a single layer on an aluminum tray within the muffle furnace to ensure a uniform heat distribution. This arrangement enabled three batches (i.e. 15 test and 15 control samples) to be subjected to $70^{\circ} \mathrm{C}$ for $2298 \mathrm{~h}$. Following this heat treatment, the samples were stored in polythene bags at room temperature for a further $336 \mathrm{~h}$ prior to impact testing. 
A Ceast Resil 25 Charpy machine with $7.5 \mathrm{~J}$ hammer, operating in accordance with BS EN ISO 179, was used for impact testing at $3.8 \mathrm{~ms}^{-1}$. In common with earlier Charpy-based studies using open-cast nylon fiber/polyester matrix samples with a low $V_{\mathrm{f}}[10,12-16]$, fibers tended to settle towards the bottom of the mold prior to curing. Thus samples were tested with the fiber-rich side facing away from the Charpy hammer and a diagram of this configuration has been previously published $[10,12,13]$. Testing was performed at $20^{\circ} \mathrm{C}$ and, as with the previous work on accelerated ageing [15], a 24 mm span was used.

\section{Results and discussion}

\section{Impact energy absorption}

Table 1 summarizes the Charpy impact data from the three batches of composite samples. Although the test samples show notable batch-to-batch variations, there is clearly an increase in impact energy absorbed (test samples relative to control counterparts) for all three batches, giving a mean increase of $39.3 \pm 9.4 \%$. This compares well with the average energy increase $(38.9 \pm 4.5 \%)$ obtained from three composite batches that had not been subjected to accelerated ageing, produced (with the same materials) and impact tested (at $336 \mathrm{~h}$ ) under the same conditions [16]. Therefore, the results in Table 1 suggest that (i) viscoelastically induced prestress from the nylon fibers remains active after the accelerated ageing process, and (ii) there appears to be no deterioration in the increased energy absorption from this prestress mechanism.

TABLE 1. Charpy impact test results from the three batches of composite samples, aged in terms of viscoelastic recovery, to an equivalent of 20000 years at $20^{\circ} \mathrm{C}: 5$ (pre-stressed) test and 5 (unstressed) control samples per batch. SE is the standard error of the mean.

\begin{tabular}{llll}
\hline \multirow{2}{*}{ Batch } & \multicolumn{2}{l}{ Batch mean impact energy $\left(\mathrm{kJm}^{-\mathbf{2}}\right)$} & \multicolumn{1}{l}{$\begin{array}{l}\text { Increase in } \\
\text { energy (\%) }\end{array}$} \\
\cline { 2 - 3 } Test $\pm \mathbf{S E}$ & Control $\pm \mathbf{S E}$ & \\
\hline 1 & $43.5 \pm 3.0$ & $34.5 \pm 1.3$ & 26.1 \\
2 & $53.4 \pm 1.0$ & $33.9 \pm 1.4$ & 57.4 \\
3 & $45.8 \pm 5.9$ & $34.1 \pm 1.4$ & 34.2 \\
\cline { 2 - 4 } Mean $\pm \mathbf{S E}$ & $\mathbf{4 7 . 5} \pm \mathbf{3 . 3}$ & $\mathbf{3 4 . 1} \pm \mathbf{1 . 3}$ & $\mathbf{3 9 . 3} \pm \mathbf{9 . 4}$ \\
\hline
\end{tabular}

Composite samples from Ref. [16] were identical to those produced for the current work, except that $V_{\mathrm{f}}$ was $3.3 \%$. This gave mean Charpy impact values of $90.6 \pm 2.3$ $\mathrm{kJm}^{-2}$ (test samples) and $65.4 \pm 2.1 \mathrm{kJm}^{-2}$ (control samples), i.e. these are almost double the corresponding values in Table 1 . Thus although Table 1 and Ref [16] show a similar pre-stress generated increase in impact energy absorption $(\sim 39 \%)$, the $50 \%$ higher nylon fiber content in Ref [16] enabled both test and control samples to absorb almost twice the impact energy due to the inherent toughness of the fibers; i.e. an effect independent of pre-stress mechanisms.

Further evidence of viscoelastically induced pre-stress remaining active for the impact-tested samples in Table 1 is shown in Fig. 3. Here, the debonded region is much greater in the test sample, extending almost over the full sample length; in contrast, 
debonding within the control sample is mainly confined to the region bounded by the vertical crack in the vicinity of the Charpy anvil shoulders, either side of the sample centre. These effects were observed for all samples evaluated in this study.

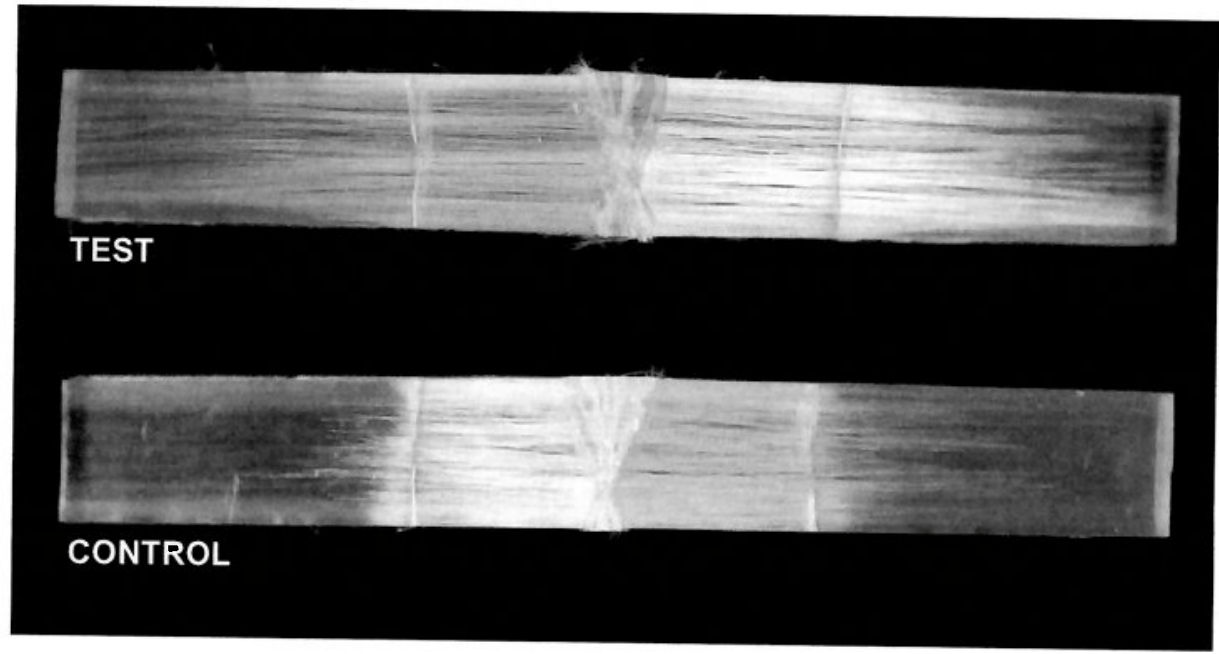

FIG. 3. Typical test (pre-stressed) and control (unstressed) samples after Charpy impact testing from the batches aged to an equivalent of $1.753 \times 10^{8} \mathrm{~h}(20000$ years $)$ at $20^{\circ} \mathrm{C}$.

The region of impact-induced debonding being much greater in the test samples is consistent with observations from previous Charpy impact studies of nylon fiber-based VPPMCs $[10,12-16,27]$. Earlier investigations on these VPPMCs eventually led to the conclusion that pre-stress induced increases in impact energy absorption may arise from four mechanisms [15]: (i) matrix compression impeding crack propagation, (ii) matrix compression attenuating dynamic overstress effects, (iii) residual fiber tension causing a more collective response to external loads and (iv) residual shear stresses at the fibermatrix interface regions promoting energy absorbing fiber debonding over transverse fracture. A more recent study [16] suggests that (iv) is the principal mechanism, i.e. pre-stress enhanced residual shear stresses between fibers and matrix are triggered to promote fiber-matrix debonding (over transverse fracture) when they are subjected to externally imposed shear stresses caused by the impact process. This shear stress triggering mechanism has also been observed in glass fiber EPPMCs [4].

\section{The long-term performance of VPPMCs}

The above findings demonstrate that the benefits from pre-stress in nylon fiberbased VPPMCs show no deterioration up to the equivalent of 20000 years at a constant $20^{\circ} \mathrm{C}$, thereby verifying the prevalence of viscoelastic activity predicted at this age by Eq. (1) in the "Background" section. As reported in the "Introduction" section, VPPMCs have a potentially major limitation, in that viscoelastic activity is temperaturesensitive and, although this can be exploited for accelerated ageing purposes, it is clear that the long-term performance of these composites must be quantified by ambient temperature as well as time.

Fig. 4 shows the new time-temperature boundary (i.e. 20000 years at $20^{\circ} \mathrm{C}$ ) established from this work. In accordance with Fig. 2, increasing the ambient temperature will reduce the duration over which VPPMCs are known not to deteriorate. 
For comparison, the previously established boundary [15] is also shown (1000 years at $20^{\circ} \mathrm{C}$ ). The slightly steeper fall-off with temperature of the new boundary arises from the gradient value in Fig. 2 being $~ 9 \%$ larger than the original value [14] used for the previous boundary in Ref. [15]. It is notable however that the new boundary indicates these VPPMCs would, for example, show no deterioration in impact performance after $\sim 25$ years at a constant $50^{\circ} \mathrm{C}$ ambient temperature. Clearly, this would make VPPMC technology viable for many, if not most practical applications.

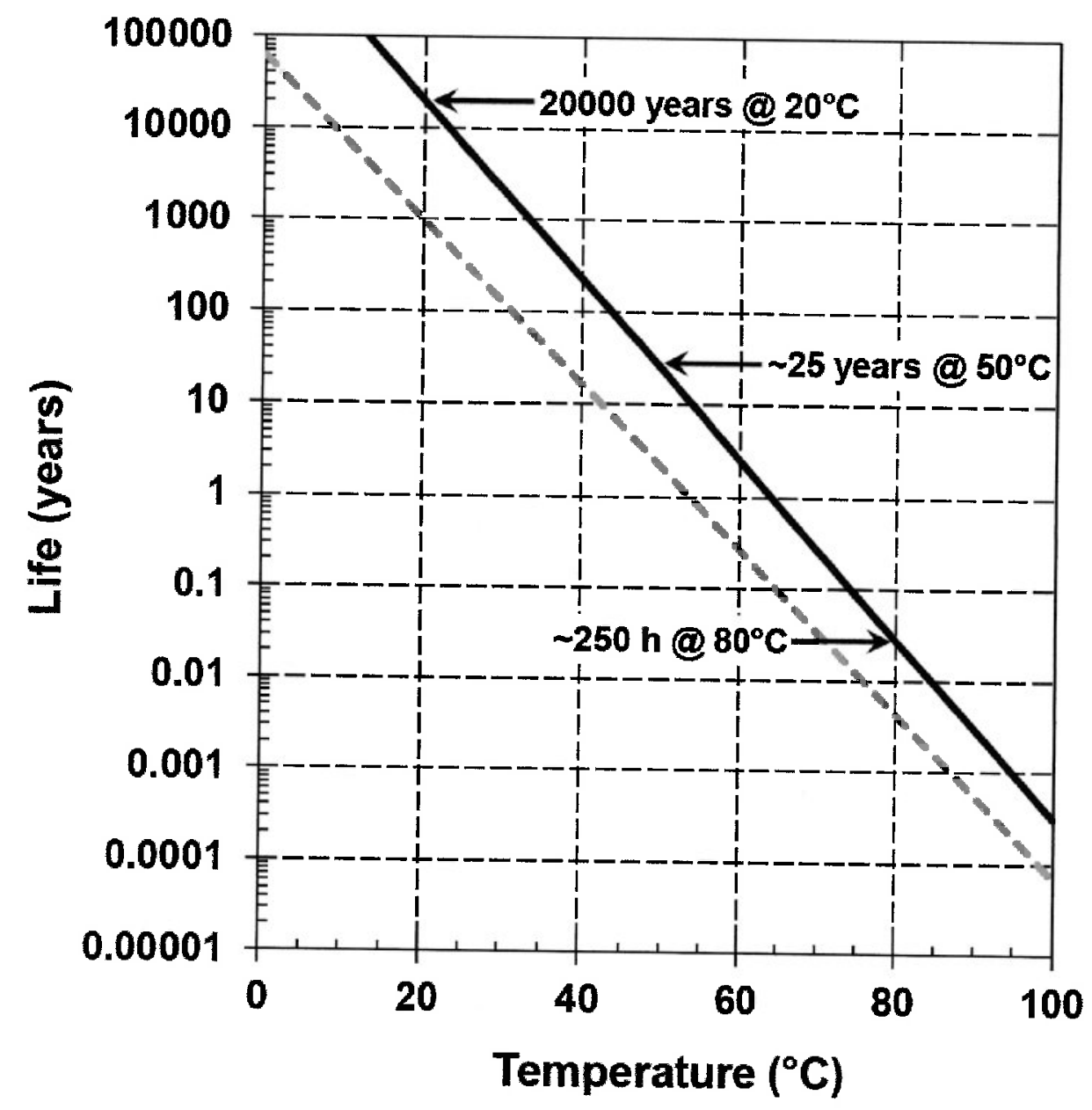

FIG. 4. VPPMC life as a function of ambient temperature (black line), based on the new timetemperature boundary, i.e. 20000 years at $20^{\circ} \mathrm{C}$. The broken (gray) line represents the previously established boundary $\left(1000\right.$ years at $\left.20^{\circ} \mathrm{C}\right)$ from Ref [15].

It is also evident from Fig. 4 that the use of high temperature matrix curing cycles for VPPMC processing remains somewhat restricted, despite the new raised boundary. That said, at $80^{\circ} \mathrm{C}$ for example, the known limit of duration from Fig. 4 would be $\sim 250$ $\mathrm{h}$. Thus several hours exposure to a moderately raised curing temperature should be possible, whilst maintaining an acceptable (subsequent) duration of operation. It is worth noting here that low temperature curing resins are of interest for applications such as aerospace, as they would allow autoclave-free curing and cheaper tooling [28,29]; therefore future developments in resins and composites manufacture may reduce the need for high temperature curing cycles. 
Elastic or viscoelastic prestressing?

Structurally, since VPPMCs require polymeric fibers with suitable viscoelastic characteristics, mechanical properties such as strength and stiffness can be expected to be inferior to EPPMCs based on glass or carbon fibers, especially when compared with nylon 6,6 fibers. Nevertheless, as reported in the "Introduction" section, VPPMCs have now been demonstrated with UHMWPE fibers, which are $\sim 4$ times stronger and $>20$ times stiffer than nylon 6,6 fibers [20,21]; hence their mechanical performance is competitive with glass and carbon fibers. VPPMC strength and stiffness properties can also be enhanced by commingling nylon 6,6 fibers (for pre-stress) with other mechanically superior fibers, such as Kevlar [27]. Since however, VPPMCs require pre-stressing fibers that are heat-sensitive (such as nylon 6,6 or UHMWPE), it may be expected that applications involving high thermal loadings would favor the use of EPPMCs.

Compared with EPPMCs, VPPMCs are a relatively recent development and this paper demonstrates that their longevity, even at elevated ambient temperatures, represents a practical product life (e.g. $\sim 25$ years at $50^{\circ} \mathrm{C}$ ). Conversely, we are not aware of any published studies on the longevity of EPPMCs; only Zhigun [1] refers to EPPMC sheets being stored at room temperature for three months prior to evaluation. As reported in the "Introduction" section, the potential influence of localized creep at the fiber-matrix interface regions is particularly important here: in contrast with prestress being maintained by viscoelastic activity in VPPMCs, the pre-stress within EPPMCs may deteriorate with age. Although high temperature curing can be used (whilst pre-stressing loads are maintained) in EPPMC production, it can be speculated that elevated temperatures in service will exacerbate the fiber-matrix creep effect, thereby shortening the useful life of EPPMCs.

\section{Conclusions}

By using time-temperature superposition principles, nylon 6,6 fiber-based VPPMC samples have been subjected to accelerated ageing. The VPPMC samples (together with control counterparts) were maintained at a constant $70^{\circ} \mathrm{C}$ for $2298 \mathrm{~h}$ ( $\sim 3.2$ months), which is equivalent to an exposure of 20000 years at $20^{\circ} \mathrm{C}$ in terms of viscoelastic recovery within the nylon fibers. This is a 20 -fold increase in ageing, over previous work. Charpy impact results from these samples suggest that viscoelastically generated pre-stress from the nylon fibers remains active after the accelerated ageing process, since there is no deterioration in increased impact energy absorption $(\sim 40 \%)$ from this pre-stress mechanism. The results have enabled a new time-temperature envelope to be established, which indicates that VPPMCs based on nylon 6,6 fibers should show no deterioration in impact performance after $\sim 25$ years at a constant $50^{\circ} \mathrm{C}$ ambient temperature.

In contrast, the longevity of EPPMCs remains open to speculation. As previously reported, progressive localized matrix creep at the fiber-matrix interface regions may cause a deterioration in elastically generated pre-stress with time; we also suggest that the effect could be exacerbated by exposure to elevated ambient temperatures. 


\section{Acknowledgements}

Support from the School of Engineering $(\mathrm{PhD}$ degree fee waiver) for one of the authors (AF) is gratefully acknowledged.

\section{References}

1. G. Zhigun, Mech. Compos. Mater., 4, 691 (1968).

2. M.E. Tuttle, J. Compos. Mater., 22, 780 (1988).

3. A.S. Hadi and J.N. Ashton, Compos. Struct., 40, 305 (1998).

4. S. Motahhari and J. Cameron, J. Reinf. Plast. Compos., 17, 123 (1998).

5. S. Motahhari and J. Cameron, J. Reinf. Plast. Compos., 18, 279 (1999).

6. L.H Schlichting, M.A.C. de Andrada, L.C.C. Vieira, G.M.D. Barra, and P. Magne, Dent. Mater., 26, 118 (2010).

7. Y. Nishi, T. Okada, S. Okada, M. Hirano, M. Matsuda, A. Matsuo, and M.C. Faudree, Mater. Trans., 55, 318 (2014).

8. S. Daynes, C.G. Diaconu, K.D. Potter, and P.M. Weaver, J. Compos. Mater., 44, $1119(2010)$.

9. S. Daynes and P.M. Weaver, Compos. Struct., 106, 282 (2013).

10. K.S. Fancey, J. Adv. Mater, , 37, 21 (2005).

11. S. Krishnamurthy, Ph.D thesis, Cranfield University, U.K. (2006).

12. K.S. Fancey, Mater. Sci. Eng. A, 279, 36 (2000).

13. K.S. Fancey, J. Reinf. Plast. Compos., 29, 1251 (2000).

14. J.W.C. Pang and K.S. Fancey, Mater. Sci. Eng. A, 431, 100 (2006).

15. K.S. Fancey, Compos. Part B, 41, 454 (2010).

16. A. Fazal and K.S. Fancey, Compos. Part B, 44, 472 (2013).

17. J.W.C. Pang and K.S. Fancey, Compos. Sci. Technol., 68, 1903 (2008).

18. J.W.C. Pang and K.S. Fancey, Compos. Part A, 40, 784 (2009).

19. H. Cui, M. Guan, Y. Zhu, and Z. Zhang, Key Eng. Mater., 517, 96 (2012).

20. A. Fazal and K.S. Fancey, J. Mater. Sci., 48, 5559 (2013).

21. A. Fazal and K.S. Fancey, Compos. Part B, 66, 1 (2014).

22. K.S. Fancey, J. Polym. Eng., 21, 489 (2001).

23. K.S. Fancey, J. Mater. Sci., 40, 4827 (2005).

24. J.W.C. Pang, B.M. Lamin, and K.S. Fancey, Mater. Lett., 62, 1693 (2008).

25. W.H. Howard and M.L. Williams, Textile Res. J., 33, 689 (1963).

26. T. Murayama, J.H. Dumbleton, and M.L. Williams, J. Macromol. Sci. (Phys.), B1, 1 (1967).

27. A. Fazal and K.S. Fancey, Polym. Compos., 35, 931 (2014).

28. C. Soutis, Plast. Rubber Compos., 38, 359 (2009).

29. F.W.J. van Hattum, F. Regel, and M. Labordus, Plast. Rubber Compos., 40, 93 (2011). 